\title{
Nuclear Division in the Dinoflagellate Gonyaulax tamarensis
}

\author{
BY J. D. DODGE \\ Department of Botany, Birkbeck College, London, W.C. 1
}

(Received 17 February 1964)

\begin{abstract}
SUMMARY
The interphase nucleus of Gonyaulax tamarensis is U-shaped with a lens-shaped central body lying between the arms of the $U$. At the beginning of division the chromosomes become arranged around the central body and can be seen to be split into pairs of chromatids which are held together by relational coiling. The pairs lie across the plane of the equator. The beginning of anaphase is obscure but as the chromatids separate into the daughter nuclei they exhibit a variety of arrangements which seem to exclude the possibility of localized centromere and normal spindle. The central body divides into two at this stage. During telophase the ball of chromosomes breaks open and the chromosomes lose some condensation as they twist together and the $U$-shaped interphase nucleus is re-established. In some of these features Gonyaulax differs from other dinoflagellates which have been studied as well as exhibiting a vastly different nuclear division to that found in higher organisms. The central body behaves like the endosome of the Euglenophyta but also has similarities with the central spindle reported from certain flagellates and diatoms.
\end{abstract}

\section{INTRODUCTION}

Recent studies of the nuclear structure and division in the Dinophyceae ( = algal division Pyrrophyta) have shown (Skoczylas, 1958; Dodge, 1963a) that the nucleus differs in many respects from the normal state found in most animals and plants. The differences are seen in the construction of the nucleus, and its component parts, and also in its behaviour during mitotic division. Earlier workers in this group reported that the nucleus had many strange attributes and some of these have now been confirmed, but many others have of necessity to be discarded. The present need is for detailed studies of a wide range of species to make it possible to see whether the nuclear behaviour of say Ceratium or Prorocentrum is the typical pattern throughout the group or alternatively whether some variety exists.

The present paper sets out to describe in some detail the nuclear division of Gonyaulax tamarensis Lebour, the nucleus of which has not been studied before. A few comparisons are made concerning the closely related species G. polyedra Stein. The nucleus in this genus, whilst showing many Dinoflagellate characteristics, also poses several new problems for investigation and interpretation. The more important of these are the considerable change in the shape of the nucleus, the anaphase segregation of chromatids and the function of what is called here the 'central body'. The genus Gonyaulax is indeed interesting and problematical. 


\section{METHODS}

Unialgal cultures of Gonyaulax tamarensis (Plymouth number 173) were supplied by Dr M. W. Parke of the Plymouth Laboratory of the Marine Biological Association of the U.K. They originated as single cell isolates made from sea water collected in the Tamar estuary where Lebour (1925) obtained material for the first description of the species. Cultures were maintained (with some difficulty) in enriched sea water under artificial illumination by the methods already described (Dodge, 1963a). Fixed material of $G$. polyedra was supplied by Dr B. M. Sweeney of Yale University.

Gonyaulax tamarensis was fixed in methanol, mordanted with ferric acetate and stained with aceto-carmine. Examination and photography were carried out on temporary preparations as previously described. The chromosomes stained readily and no special methods were needed.

\section{RESULTS \\ The interphase nucleus}

The non-dividing nucleus of Gonyaulax (both species) must be one of the most unusual yet recorded for any organism, perhaps with the exception of the macronuclei of certain ciliates. The typical form can be seen in Fig. $1 \mathrm{~A}$ and Pl. 1, fig. 1, which show the horseshoe or U-shape. This form is lost during division. Only one other member of the Dinophyceae, a freshwater Peridinium species, is known to have a similar nucleus. The chromatin consists of long intertwined threads which are clearly chromosomes, although often they are not so strongly condensed as are the interphase chromosomes of Prorocentrum (Dodge, 1963a). They appear to be arranged more or less spirally in the nucleus, but the large number makes it impossible to follow the orientation of any individual chromosomes. The smooth outline of the nucleus with no projecting chromosomes (unlike Prorocentrum) suggests the presence of a membrane around the nucleus at this stage.

The interphase chromosomes stain readily with the Feulgen stain, which Hastings \& Sweeney (1964) have also observed for Gonyaulax polyedra, and with methyl green. As with other Dinoflagellates (Dodge, 1964) the chromosomes appear to contain a considerable amount of deoxyribose nucleic acid (DNA).

Situated between the arms of the nucleus is a large, almost structureless, lensshaped body (Fig. 1; Pl. 1, fig. 1). This body is probably homologous with the nucleolus of other organisms. However, because of its strange behaviour during mitosis (see later) and its position adjacent to the interphase nucleus but not within it, the non-committal term 'central body' will be used to describe it. The central body contains no DNA but does appear to contain ribose nucleic acid as evidenced by a certain amount of staining with pyronin.

\section{The nucleus in division}

The first indication that nuclear division is about to commence is seen when the nucleus begins to change its shape. The $U$-shape is obviously an inconvenient one for the processes involved in mitosis. Thus the distal ends of the nucleus come together and the whole nucleus forms a ball around the central body (Fig. 1B, C). The chromosomes, whilst becoming more condensed, are also reorientated and take up 
the position of lines of longitude around a globe, the central body being visible at the top and bottom as 'polar caps'. Towards the end of this process it becomes clear that the chromosomes have split longitudinally into pairs of relationally coiled chromatids. A simplification of such a stage is shown in Fig. $1 \mathrm{D}$ and two focal levels of an
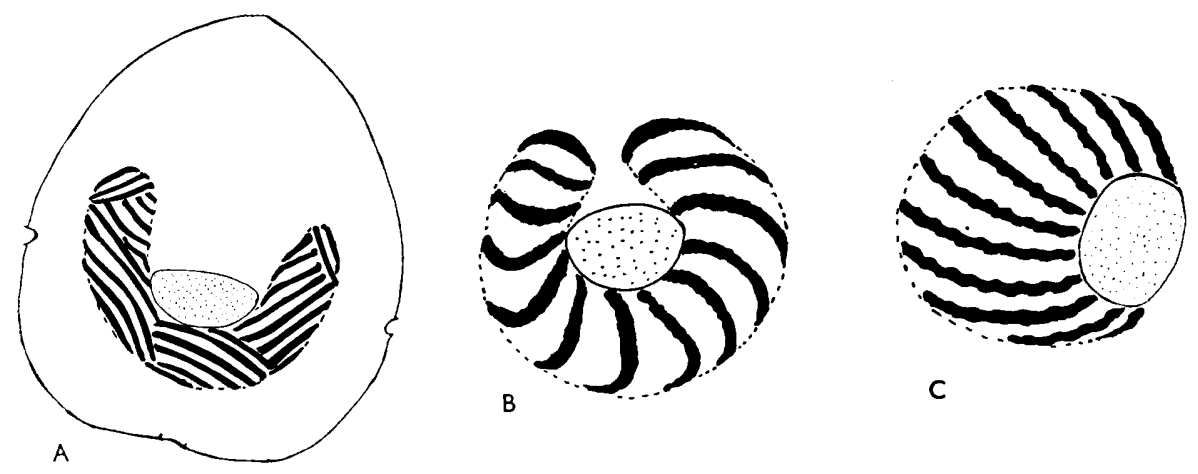

C

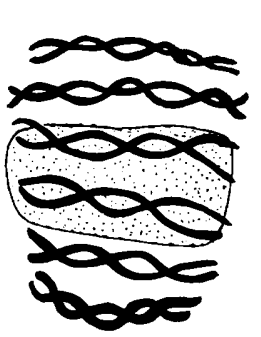

D
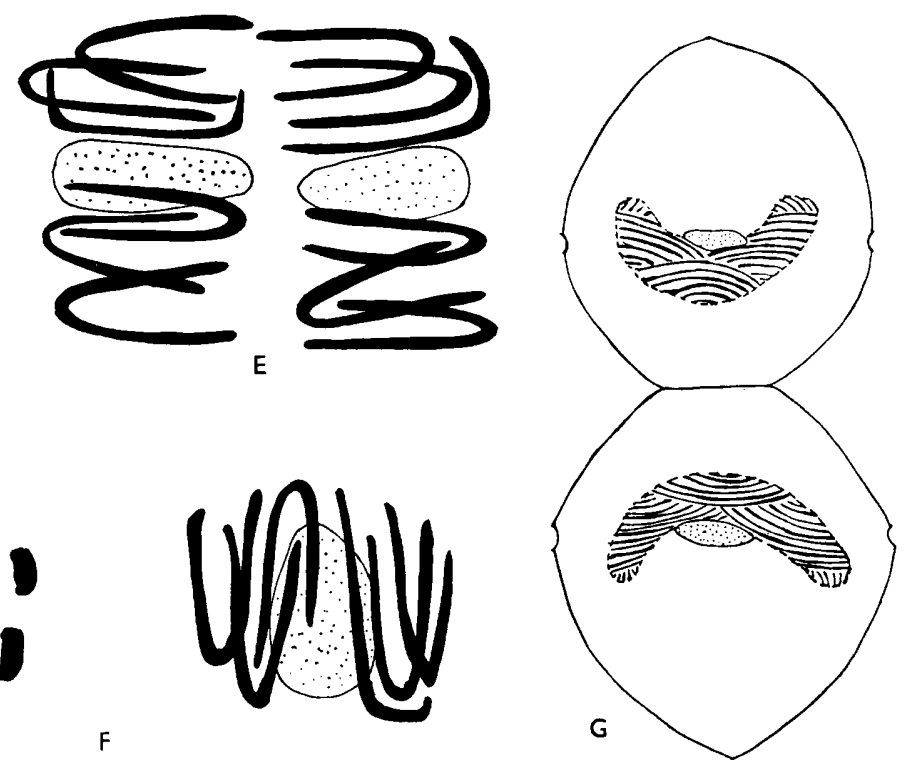

Fig. 1. Diagrams to illustrate some of the processes taking place in the mitosis of Gonyaulax. For clarity only a small number of chromosomes are shown (not all to same scale). A. Cell with interphase nucleus and central body. B. Early prophase: the arms of the nucleus begin to wrap around the central body; the chromosomes become more distinct. C. Mid-prophase 'globe' formation now complete. D. Late prophase or pre-metaphase, chromosomes split into pairs relationally coiled together and lying parallel to the central body. E. Mid-anaphase, showing some of the shapes of the separating chromatids. F. Late anaphase: change of orientation of daughter nuclei has begun; one nucleus in polar view, other in side view (cf. Pl. 4, fig. 13). G. Telophase. The interphase state of nucleus almost re-established but cell cleavage is not quite complete.

actual nucleus are shown in Pl.1, figs. 2, 3. In Pl. 1, fig. 3, the focal level passes through the central body, which does not stain with aceto-carmine and so is observed only as a region lacking chromosomes. This mitotic figure shows the considerable tangle which 
exists due to the large number of very long chromosomes. However, it is clear that the orientation of the pairs of chromatids is mainly at right-angles to the 'equator' and parallel to the central body. This stage might best be described as a prometaphase. If a nuclear membrane is present around the interphase nucleus it has clearly disappeared by now.

The chromatids probably contract somewhat in length, and by rotation lose the relational coils which have been holding sister chromatids together. The anaphase separation possibly begins whilst this process is taking place. Plate 1, fig. 4, shows an early anaphase where separation has just begun, but the tangling of the chromatids and the depth of the nucleus effectively conceals the method being employed.

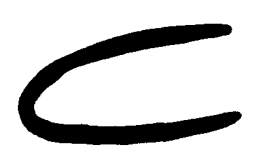

A

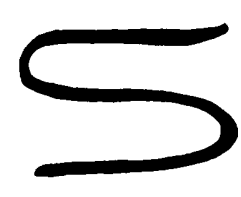

C

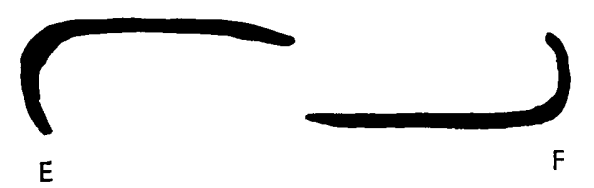

Fig. 2. Diagrams illustrating some of the shapes shown by separating chromatids at midanaphase, in situ the 'equator' would be situated to the right of the figure. A, B are very common types and $\mathrm{C}-\mathrm{F}$ are rather rare. (Details in text.)

When the daughter groups of chromatids have completely separated from one another at mid-anaphase the orientation of individuals can be more clearly discerned (Fig. 1 E; Pl. 2, figs. 5-8; Pl. 3, figs. 9-12). A careful analysis of such stages has shown the chromatids to be arranged in at least six different ways (Fig. 2A-F). The most frequent form is the $U$-shape (Fig. $2 \mathrm{~A}, \mathrm{~B}$ ), which can have the open end of the $U$ pointing either towards the 'equator' or towards the 'poles'. The S-shapes (Fig. 2C, D) are less frequent and could conceivably be misinterpretations of two oppositely orientated $U$-shaped chromosomes lying partly over each other. Alternatively, it may be that the $S$ is the normal form and the $U$ is a misunderstanding of the parts of the S. Another arrangement is the right-angle type (Fig. $2 \mathrm{E}, \mathrm{F}$ ) with the short arm either at the polar or the equatorial end of the daughter nucleus.

At first it was thought that the normal arrangement here was the very unusual one (type A or B) of the chromatids in one nucleus with their open end (of the $U$ ) facing the equator and in the other the open end facing the pole. This was found to be an over-simplification for when a careful analysis was made of all the $U$-shaped 
chromatids which could be clearly distinguished in photographs of eight anaphases, results were obtained which made this seem unlikely (see Table 1).

Assuming that any chromatid shape found in one daughter nucleus would be either the same or the opposite of what its sister chromatid formed in the other daughter nucleus we can suggest four possible combinations of chromatids all of which should give rise to a one to one ratio between the two nuclei. From the table it can be seen that the two unusual types $A$ and $B$ gave ratios of $3: 1$ and $1: 2$ respectively. These therefore appear unlikely to be the normal arrangements of the separating chromatids. The third type (X), which is also the usual type found in higher

Table 1. The shape and arrangement of certain chromatid types in the mid-anaphase of Gonyaulax

\begin{tabular}{|c|c|c|c|}
\hline \multirow{2}{*}{\multicolumn{2}{|c|}{$\begin{array}{l}\text { Arrangement of } \\
\text { chromatids in the } \\
\text { daughter nuclei }\end{array}$}} & \multicolumn{2}{|c|}{ No. of chromatids } \\
\hline & & $\begin{array}{c}\text { Left } \\
\text { nucleus }\end{array}$ & $\begin{array}{c}\text { Right } \\
\text { nucleus }\end{array}$ \\
\hline $\mathbf{A}$ & $\subset \subset$ & 45 & 15 \\
\hline $\mathbf{B}$ & $\supset \supset$ & 22 & 43 \\
\hline $\mathbf{x}$ & $\subset \supset$ & 45 & 43 \\
\hline $\mathbf{Y}$ & $\supset \subset$ & 22 & 15 \\
\hline
\end{tabular}

$\begin{array}{cc}\text { Expected } & \text { Found } \\ \text { left nucleus : right } & \text { Found } \\ 1: 1 & 3: 1 \\ 1: 1 & 1: 2 \\ 1: 1 & 1: 1 \\ 1: 1 & 4: 3\end{array}$

plants (although there the form is more $V$-shaped), will be seen to give a clear $1: 1$ ratio, which is also very nearly given by the opposite of the usual arrangement in the fourth possibility (Y). As two-thirds of the chromatids which were analysed could be said to be in type $X$ and as this gave the expected ratio it would seem likely that this is the normal manner of mid-anaphase separation. However, from the large number of chromatids giving other shapes, such as the $\mathbf{3 7}$ in the table and the $S$ and right-angle forms mentioned earlier, it is clear that the process is not uniform and that the division mechanism used here allows much scope for variety of chromatid form.

The central body is in existence throughout the anaphase and can clearly be discerned (Pl. 3, figs. 9, 10) as a chromosome-free region running through the centre of the nucleus. At this mid-anaphase stage it had become divided into two and one half remained in each daughter nucleus.

The late anaphase exhibits two processes, the further separation of the two daughter nuclei combined with a change in orientation of each through ninety degrees. Such a stage is shown in Pl. 4, fig. 13, where one daughter nucleus can be seen in a 'polar' view and the other from the side. In the former the central body is surrounded by concentric rings of chromosomes, perhaps as many as $\mathbf{1 5 0}$ in number (Dodge, $1963 \mathrm{~b}$ ). In the latter a focal section gives a picture of the chromosomes lying alongside the central body.

The final stage of the division, telophase, is occupied as is usual by the reconstitution of the interphase nucleus. This takes place by a reversal of the early prophase changes; the chromosomes of each daughter nucleus separate opposite the anterior end of the new cell and, perhaps whilst becoming less condensed and being arranged in a somewhat spiral fashion, are partially detached from the central body to give the two arms of the nucleus. In Pl. 4, fig. 14, is shown a pair of cells in which this process has just occurred and the two new interphase nuclei can be seen to be mirror images of each other. Finally the two daughter cells, which have been acquiring 
their own cell walls since late anaphase, separate and the nuclear and cell division is complete.

Gonyaulax polyedra has been briefly examined (and by Hastings \& Sweeney, 1964). The stages which were observed appeared to be identical with those described above for $G$. tamarensis.

\section{DISCUSSION}

The nuclear division of Gonyaulax is unusual if not unique. Not only does it possess the characteristic Dinoflagellate features of permanent condensation of the chromosomes and the pre-anaphase arrangement of the pairs of chromatids across the plane of the equator, but it also has its own distinctive changes in the shape of the nucleus and the strange behaviour of the central body. At present very few representatives of the Dinophyceae have been studied and although these represent a fair range of genera it is quite possible that a similar behaviour will be found in other organisms belonging to this group.

One of the major problems in Gonyaulax is the process of anaphase separation of the sister chromatids. The vital early stage is made so complicated by the large number of long chromatids that little detail has so far been observed. It is obviously insufficient to say that 'the nucleus pulls apart like a skein of yarn' (Hastings \& Sweeney, 1964), but do the chromatids separate by a gliding movement as seems to happen in Prorocentrum (Dodge 1963a), or are they pulled apart first from their mid-points leaving the distal arms to unwind as reported for Ceratium (Skoczylas, 1958), or is a completely different process in operation here? At a slightly later stage of anaphase it is possible to make out the configuration of many of the separating chromatids. This has revealed that, as in certain members of the Euglenophyta (Leedale, 1958), a considerable variety of chromatid shapes are present. Although the majority of the chromatids counted in the present study showed what may be called the typical $U$-shape, facing the equator, it would be unwise to make any deductions about the mechanism of anaphase movement for, as has been found in Prorocentrum, this shape can quite easily be due to secondary factors after the main separation has taken place. One other important fact is that neither in the Euglenophyta (Leedale, 1958) or in Gonyaulax is there any evidence for diffuse centromeres or a normal spindle. This fact is disputed by Skoczylas (1958) and von Stosch (1958), who recognize both localized centromere and spindle in Ceratium, but the variety of chromatid arrangement in Gonyaulax definitely argues against this for spindle and centromeres should surely result in a more or less uniform, ordered, anaphase segregation.

The central body provides another interesting problem. In appearance and behaviour it is not unlike the central spindle which has been described for many members of the Hypermastigina (as Barbulanympha-Cleveland, 1958), but in these organisms the spindle arises from prominent centrioles which do not appear to be present in Gonyaulax or any other Dinoflagellate. Central spindles have also been described for a number of diatoms (Lauterborn, 1896; Geitler, 1927) and for the strange flagellate (perhaps Dinoflagellate) Noctiluca (Ishikawa, 1894; Calkins, 1899). The function of the central spindle in Barbulanympha is said to be purely passive, providing a track for the chromosomes to be pulled along by traction fibres rather like those found in a normal spindle. 
In several respects the central body is similar to the endosome (= persistent nucleolus) which is universally present in the Euglenophyta (Leedale, 1958; and earlier workers) and which is also present in at least one member of the Dinophyceae, Oxyrrhis marina (Hall, 1925; Dodge, 1963a). Although the endosome usually becomes stained in cytological preparations, which the central body does not, during division its behaviour is almost identical with that of the central body as it normally runs through the centre of the dividing nucleus and breaks into two at anaphase. In Euglena and perhaps Oxyrrhis a persistent nuclear membrane surrounds chromosomes and endosome. In Gonyaulax, however, there is clearly no membrane around the dividing nucleus and there is little evidence for the presence of a membrane during the interphase.

It is easy to visualize some form of connexion between certain of the chromosomes and the central body perhaps like the nucleolar-organizing chromosomes known from many other organisms. If this is in fact the case in Gonyaulax and if further investigation suggests that the central body plays an active part in the division processes of anaphase separation and the changes in shape of the nucleus, then it may be necessary to revert to the traditional terminology of 'central spindle' for this body.

I am grateful to Dr M. W. Parke for supplying the cultures of Gonyaulax tamarensis and to Dr B. M. Sweeney for the fixed material of G. polyedra.

\section{REFERENCES}

CaLkins, G. N. (1899). Mitosis in Noctiluca milearis and its bearing on the nuclear relations of the Protozoa and Metazoa. J. Morph. 15, 711.

Cleveland, L. R. (1958). A factual analysis of chromosomal movement in Barbulanympha. J. Protozool. 5, 47.

Dodge, J. D. $(1963 a)$. The nucleus and nuclear division in the Dinophyceae. Arch. Protistenk. 106, 442.

Dodge, J. D. (1963b). Chromosome counts in some marine Dinoflagellates. Bot. marina, $5,121$.

Dodge, J. D. (1964). Chromosome structure in the Dinophyceae. II. Cytochemical studies. Arch. Mikrobiol. 48, 66-80.

Geitler, L. (1927). Reductionsteilung, Copulation und Parthenogenese bei Cocconcis placentula. Arch. Protistenk. 59, 506.

Hall, R. P. (1925). Binary fission in Oxyrrhis marina Dujardin. Univ. Calif. Publ. Zool. 26, 281.

Hastings, J. W. \& Sweeney, B. M. (1964). Phased cell division in the marine Dinoflagellates. In Synchrony in Cell Division. New York: J. Wiley.

Ishikawa, C. (1894). Studies of reproductive elements. II. Noctiluca milearis, its division and spore formation. J. Coll. Sci. Imp. Univ. Japan, 6, 297.

LaUterbonn, R. (1896). Untersuchungen über Bau, Kernteilung und Bezcegung der Diatomeen. Leipzig: W. Engelmann.

Lebour, M. (1925). The Dinoflagellates of Northern Seas. Plymouth: Mar. biol. Assn. (UK).

Leedale, G. F. (1958). Nuclear structure and mitosis in the Euglenineae. Arch. Mikrobiol. 32, 32.

Skoczylas, O. (1958). Über die Mitose von Ceratium cornutum und einigen anderen Peridineen. Arch. Protistenk. 103, 193.

Stosch, H. A. von (1958). Zum Chromosomenformwechsel der Dinophyten sowie zur Mechanik und Terminologie von Schrauben. Arch. Protistenk. 103, 229. 


\section{EXPLANATION OF PLATES}

All photographs are of aceto-carmine-stained cells in temporary preparations of Gonyaulax tamarensis $\times \mathbf{2 0 0 0}$.

\section{Plate 1}

Fig. 1. Interphase nucleus showing the appearance of the tightly wound chromosomes and the large central body between the two arms of the nucleus.

Figs. 2, 3. Two focal levels of a late prophase nucleus. Note the central body in fig. 3 and the pairs of chromatids lying more or less parallel to this.

Fig. 4. A very early anaphase showing the beginning of chromatid separation (top focal level).

\section{Plates 2 and 3}

Figs. 5-12. Here four pairs of photographs illustrate four focal levels through a single mid-anaphase division stage. In the second print of each pair (right-hand side) some of the chromosomes have been overdrawn with indian ink to make more clear the variety of shapes exhibited at this stage (for further explanation see text). In figs. 9, 10 note the clear central region in both daughter groups of chromosomes which is due to the presence of the divided central body.

\section{Plate 4}

Fig. 13. A late anaphase with the daughter nucleus at the left in 'polar' view and at the right in side view and optical section.

Fig. 14. The end of division with the interphase nuclei now re-established and cell cleavage almost complete. 


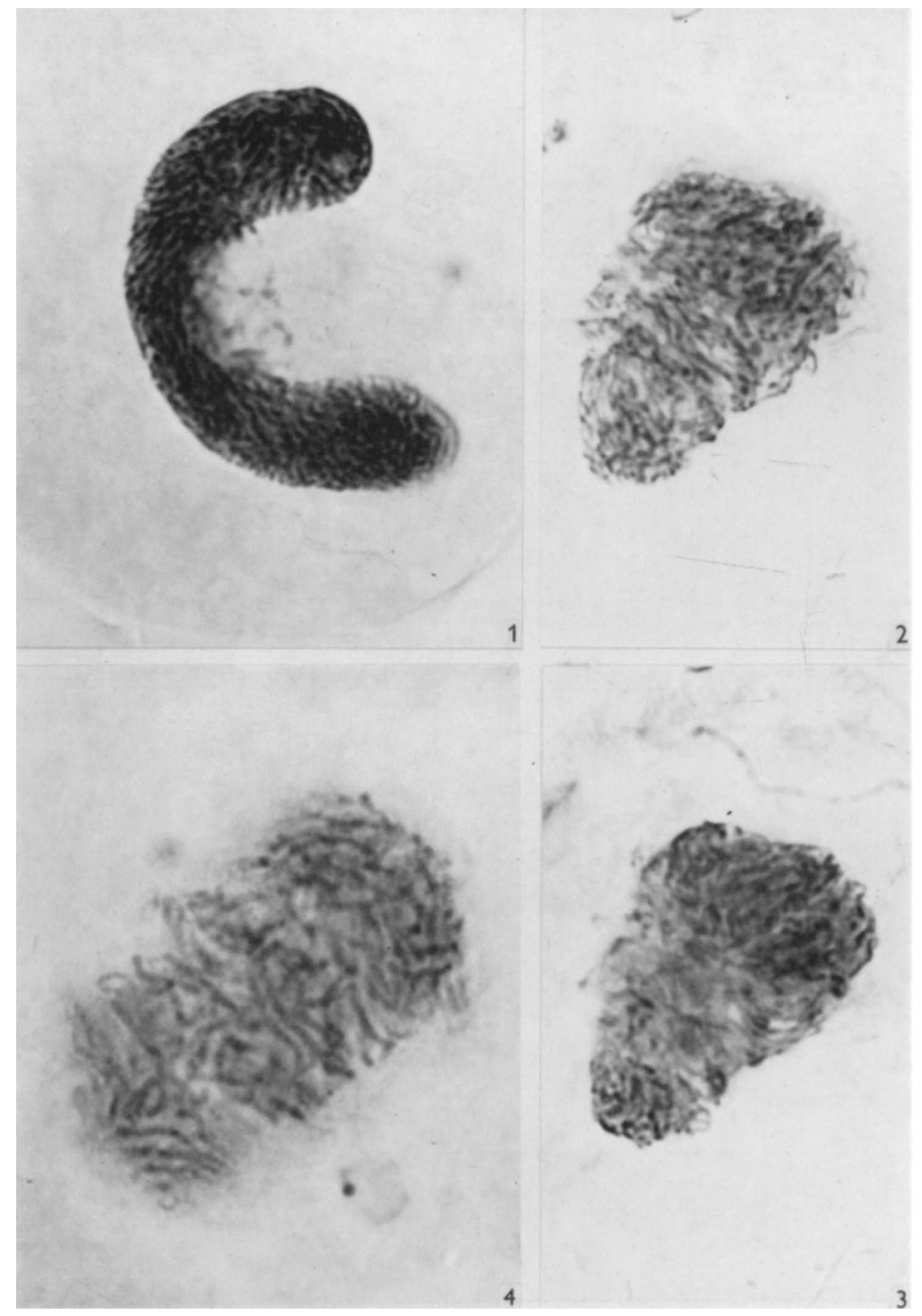

J. D. DODGE

(Facing p. 276) 
Journal of General Microbiology, Vol. 36, No. 2

Plate 2

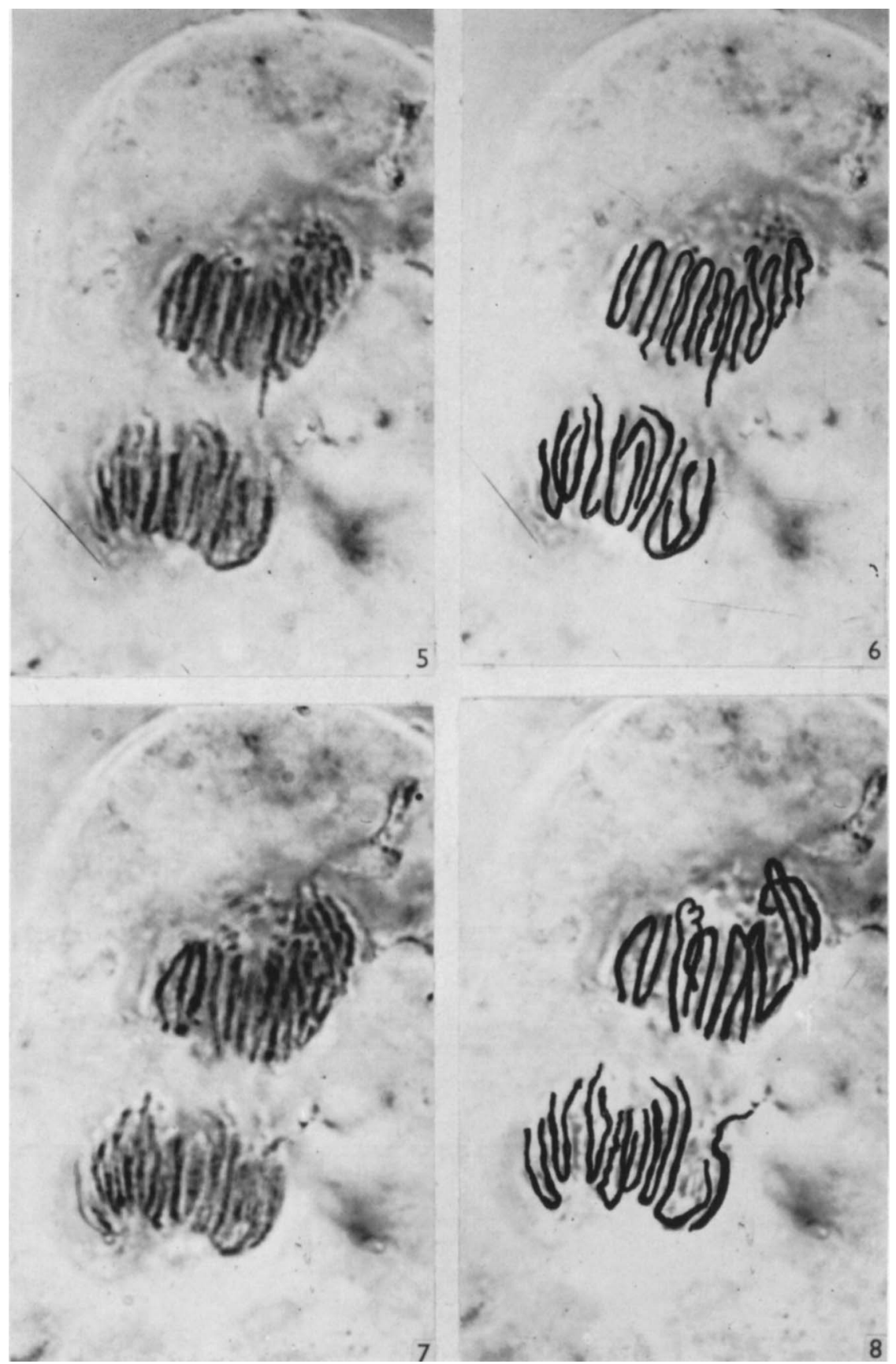

J. D. DODGE 
Journal of General Microbiology, Vol. 36, No. 2

Plate 3

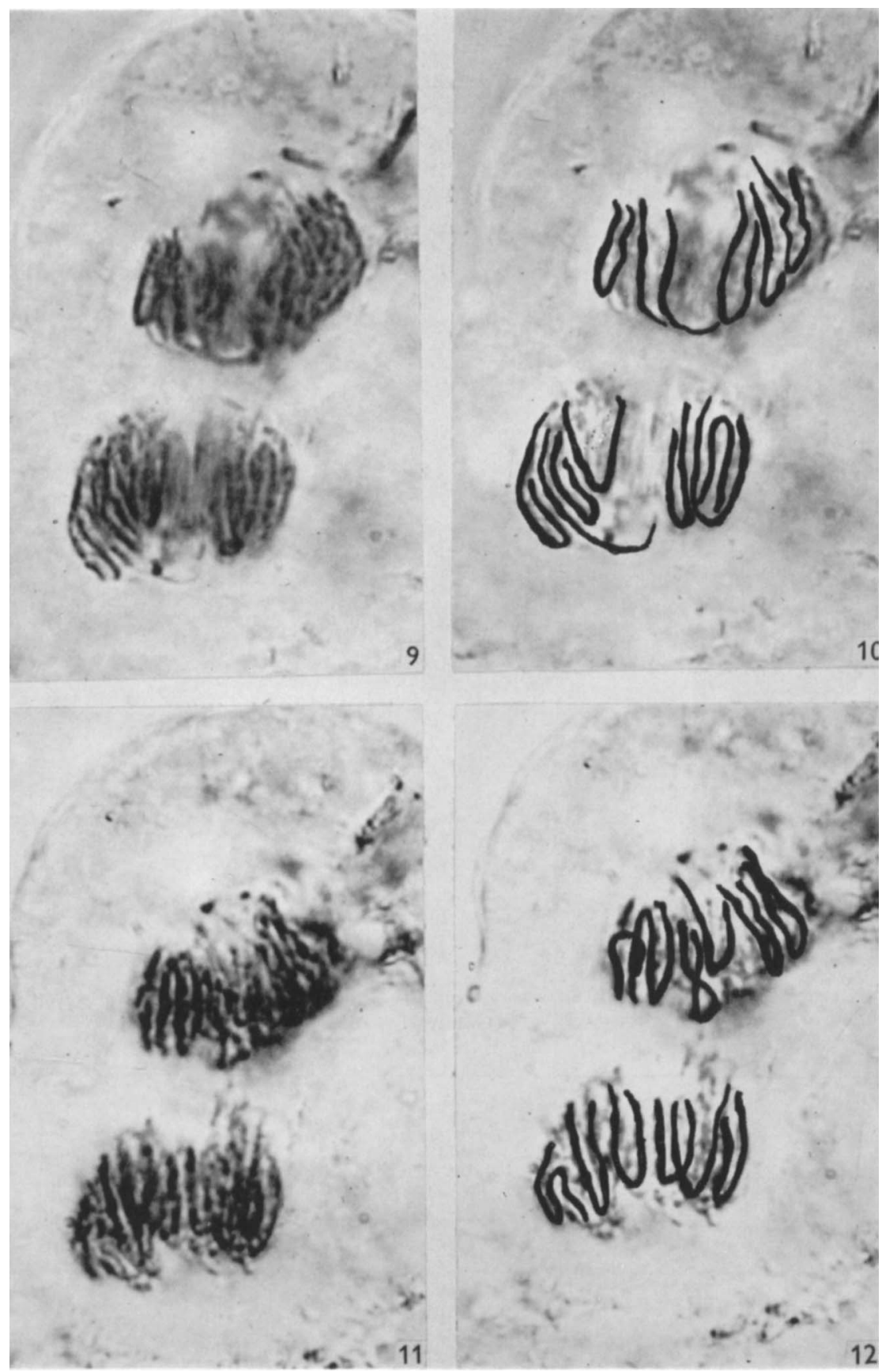

J. D. DODGE 

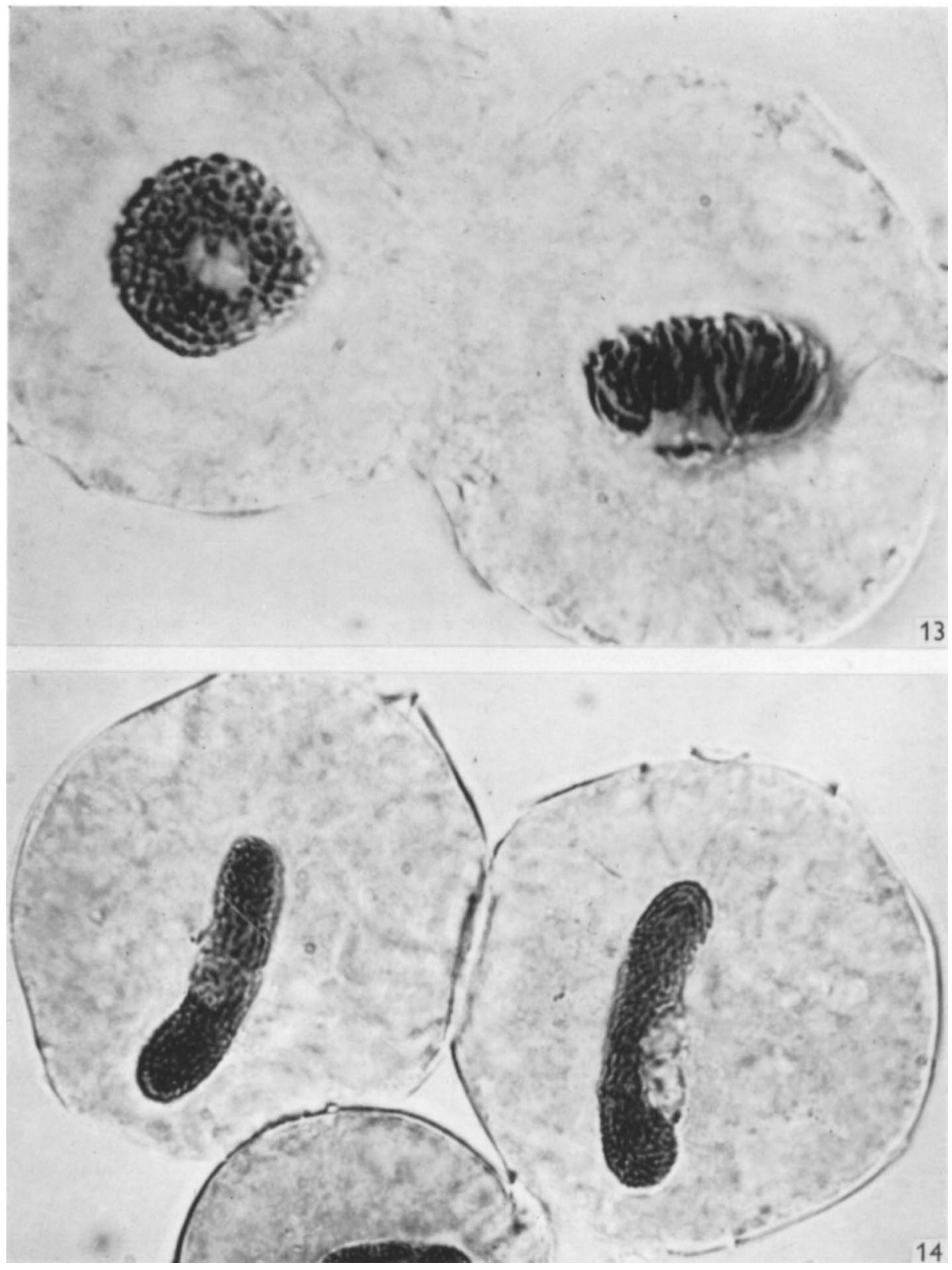

J. D. DODGE 